\title{
Characterization of the Vectron PX-570 Crystal Oscillator for Use in Harsh Environments
}

\author{
Jacob Li, \\ Vectron International \\ 267 Lowell Rd. \\ Hudson, NH 03051 \\ (603) 578-3042,jli@vectron.com \\ Richard L. Patterson \\ NASA Glenn Research Center \\ M.S. 309-2 \\ Cleveland, Ohio 44135 \\ (216) 433-8166, Richard.Patterson@grc.nasa.gov \\ Ahmad Hammoud \\ ASRC Aerospace, Inc. \\ NASA Glenn Research Center \\ Cleveland, Ohio 44135, Ahmad.Hammoud@grc.nasa.gov
}

\begin{abstract}
Computing hardware, data-acquisition systems, communications systems, and many electronic control systems require well-controlled timing signals for proper and accurate operation. These signals are, in most cases, provided by circuits that employ crystal oscillators due to availability, cost, ease of operation, and accuracy. In some cases, the electronic systems are expected to survive and operate under harsh conditions that include exposure to extreme temperatures. These applications exist in terrestrial systems as well as in aerospace products. Well-logging, geothermal systems, and industrial process control are examples of ground-based applications, while distributed jet engine control in aircraft, space-based observatories (such as the James Webb Space Telescope), satellites, and lunar and planetary landers are typical environments where electronics are exposed to harsh operating conditions.

To ensure these devices produce reliable results, the digital heartbeat from the oscillator must deliver a stable signal that is not affected by external temperature or other conditions. One such solution is a recently introduced commercial-off-the-shelf (COTS) oscillator, the PX-570 series from Vectron International. The oscillator was designed for high-temperature applications and as proof, the crystal oscillator was subjected to a wide suite of tests to determine its ruggedness for operation in harsh environments.

The tests performed by Vectron included electrical characterization under wide range of temperature, accelerated life test/aging, shock and vibration, internal moisture analysis, ESD threshold, and latch-up testing. The parametric evaluation was performed on the oscillator's frequency, output signal rise and fall times, duty cycle, and supply current over the temperature range of $-125^{\circ} \mathrm{C}$ to $+230{ }^{\circ} \mathrm{C}$. The evaluations also determined the effects of thermal cycling and the oscillator's re-start capability at extreme hot and cold temperatures. These thermal cycling and restart tests were performed at the NASA Glenn Research Center. Overall, the crystal oscillator performed well and demonstrated very good frequency stability. This paper will discuss the test procedures and present details of the performance results.
\end{abstract}

Key Words: High Temperature, Harsh Environment Electronics, Cyrogenic, Shock \& Vibration, Crystal Oscillator

\section{Introduction}

Electronic components that are able to operate in an ambient temperature range of $-40^{\circ} \mathrm{C}$ to $+85^{\circ} \mathrm{C}$ are usually considerable "industrial" grade. If they are specified to operate in an ambient temperature range of $-55 /-65{ }^{\circ} \mathrm{C}$ to $+125^{\circ} \mathrm{C}$, they are considered to be 'mil-spec' devices. There are some situations where 
operation below $-65^{\circ} \mathrm{C}$ (without heating) is desirable; that would be considered low temperature operation. In a similar manner, high temperature operation is considered above $125^{\circ} \mathrm{C}$.

Low temperature operation takes place on earth occasionally in polar regions, and in space at locations that are always in shadow (especially away from the sun), such as polar craters on the moon or behind the sun shield of the James Webb Space Telescope (both near 35 Kelvins). Other examples would include low temperature science experiments, superconducting magnetic energy storage, magnetic resonance imaging, and magnetic levitation systems. Some electronics may have to operate down near absolute zero temperature.

High temperature uses would include automotive, jet and rocket engines, volcano science, and downhole equipment for gas, oil, and geothermal wells. Some terrestrial projects would operate at 150 to 200 ${ }^{\circ} \mathrm{C}$. Some would like $300{ }^{\circ} \mathrm{C}$; others would require $600{ }^{\circ} \mathrm{C}$ or higher. Hot space equipment would include those working close to the sun.

Most electronic equipment is not manufactured for operation at extreme ambient temperatures. As a result, extreme temperature electronics designers have the approach:

1. Select only those active and passive devices that are manufactured using materials and processes that will yield a device that can operate over the required range of operating temperatures including extreme low or high or both temperatures.

2. Evaluate/characterize the selected devices over the range of the required operating temperatures.

3. Build evaluation and prototype circuits using boards and solders that will operate over the required temperature range.

4. Test and test and test. Consider performing thermal cycling, radiation, and overstressing tests.

The use of extreme temperature electronics does have advantages. At low temperatures you do not have to include heating systems that use up energy and add to increased mass and complexity. At high temperatures you do not have to include cooling systems that increase mass and complexity. The advantages of low temperature electronics include improved reliability and lower $\mathrm{R}_{\mathrm{ds} \text { on }}$ (for MOSFETs). High temperature electronics has the advantage of getting the first amplifier/processor in close to a measuring transducer so that a high level signal can be sent down a later/longer data line.

\section{Oscillator Overview}

The PX-570 series oscillators were fabricated using proprietary manufacturing processes designed specifically for high temperature and harsh environment applications [1]. The physical package of the PX-570 HT XO is custom designed and the component substrate was fabricated with multilayer high-temperature co-fired ceramic (HTCC) technology. Due to the multilayer structure, Vectron was able to design unique 3-D features inside the package to improve the shock and vibration performance and the component assembly processes.

The quartz resonator at the heart of the PX-570 was specially designed for harsh environment applications. In-house design algorithms were used to determine the correct cut angles and quartz resonator blank geometry to optimize performance over the wide temperature range. The quartz resonator requires specialized crystal angle for harsh environment applications and such resonators are not common to traditional frequency control products.

Vectron has the capability to fabricate this type of quartz resonators from a quartz bar to the finished quartz resonator blank via cutting, lapping, surface contouring, X-ray angle correction, polishing and beveling processes. Specialized etch chemistries were also used for tailoring custom crystal angle cut to meet custom harsh environment crystal oscillator requirements. The quartz resonator electrode was also designed with a unique metallization scheme to overcome issues that would affect the long term stability of the oscillators under harsh environmental conditions.

Additionally, residual mounting stress can be caused by stiffness of the crystal mounting clips, and shrinkage or expansion of the mounting adhesive (Figure 1a). However, the unique PX-570 quartz resonator mounting structure has successfully addressed and resolved these residual mounting stress issues which can affect the performance of the quartz resonator over a wide temperature range. 


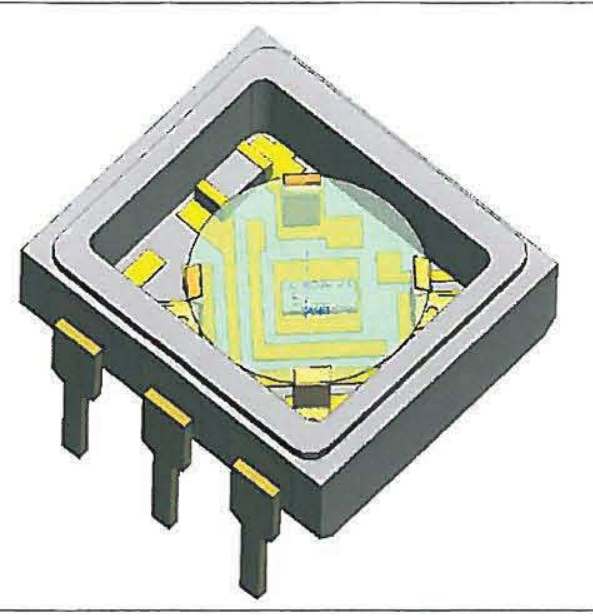

Figure 1a. Inside the PX-570 oscillator, a custom designed crystal and mounting scheme minimize stress to the crystal and allow the oscillator to operate over a wide temperature range.

Able to operate over a wide, continuous temperature range, the oscillators are ideal for use in oilfield downhole tools, military and aerospace systems, industrial process control, geophysical fields, avionics, and engine control applications. The oscillators exhibit low jitter and low phase noise, consume little power, and are suited for high shock and vibration applications. The unique package design of these crystal oscillators offers a small ceramic package footprint, as well as providing both through-hole mounting and surface mount options. Table I shows some of the manufacturer's specifications for this device [1].

Table I. Manufacturer's specifications of PX-570 crystal oscillator [1]

\begin{tabular}{|c|c|}
\hline Parsmeter & {$\left[\begin{array}{rr}02 \\
4 & 00000\end{array}\right.$} \\
\hline Operating voltage (V) & 3.3 \\
\hline Frequency (MHz) & 10 \\
\hline Input current (mA) & 5 \\
\hline Operating temperature $\left({ }^{\circ} \mathrm{C}\right)$ & 0 to +230 \\
\hline Duty cycle $(\%)$ & 40 to 60 \\
\hline Frequency tolerance (ppm) & \pm 300 \\
\hline Output rise/fall time (ns) & 1 to 3 \\
\hline RoHS Compliant. ceramic leaded package & 6.pin $8.0 \mathrm{~mm} \times 8.5 \mathrm{~mm}$ \\
\hline Part \# & PX-5701-EA3 YXXX-10M \\
\hline Lot number & $256280-1122$ \\
\hline
\end{tabular}

Operation stability of the crystal oscillator was evaluated with the device exposed to extreme temperatures. Performance characterization was done by observing the oscillator's output frequency, duty cycle, rise and fall times, and supply current at specific test temperatures. Re-start capability at extreme temperatures, i.e. power switched on while the device was soaking at extreme (hot or cold) temperature, was also examined at NASA Glenn
Research Center. The effects of thermal cycling under a wide temperature range on the operation of the crystal oscillator were also investigated. The oscillator was subjected to a total of 12 cycles in the temperature range of $-125{ }^{\circ} \mathrm{C}$ to $+230{ }^{\circ} \mathrm{C}$ at a temperature rate of $10{ }^{\circ} \mathrm{C} /$ minute and a soak time of 20 minutes at the temperature extremes. A simple test board, populated with the PX-570 and a few filter capacitors was used during the characterization tests (Figure 1b).

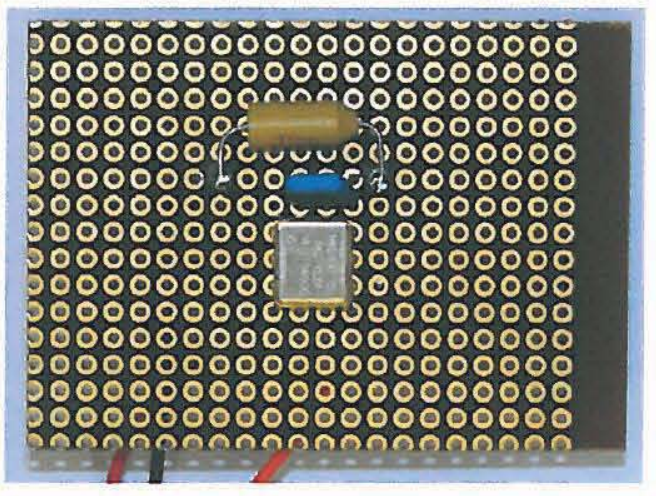

Figure $1 b$. Oscillator package and filter capacitors mounted on the PC board used for performance testing.

\section{Temperature Effects}

The output frequency of the PX-570 crystal oscillator as a function of temperature is shown in Figure 2. The oscillator operated successfully throughout the entire test temperature range of -125 ${ }^{\circ} \mathrm{C}$ to $+230{ }^{\circ} \mathrm{C}$ with very slight variation in its output frequency, most notably at the extreme high temperatures. These variations, as depicted in Figure 2 , are reflected by a gradual but slight increase in the output frequency of the oscillator as the applied test temperature was above $+180^{\circ} \mathrm{C}$. At the highest test temperature of $+230^{\circ} \mathrm{C}$, for example, the oscillator's frequency attained a value of $10.0052 \mathrm{MHz}$ as compared to the room temperature magnitude of $9.9993 \mathrm{MHz}$. This increase in frequency amounted to $0.06 \%$ 


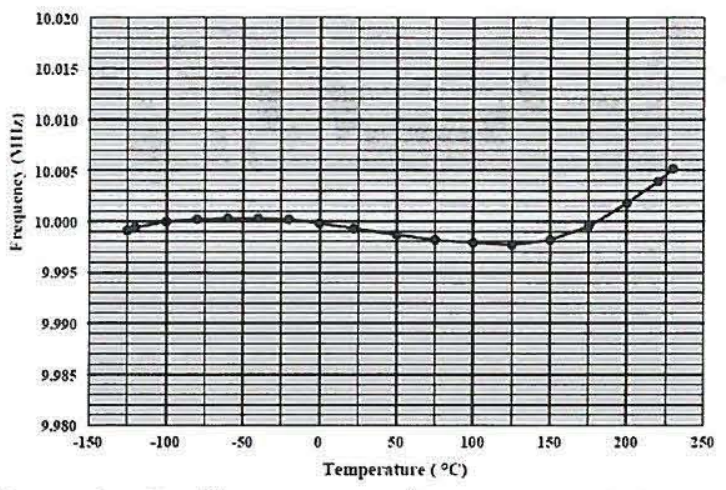

Figure 2. Oscillator output frequency variation as temperature goes from $-150^{\circ} \mathrm{C}$ to $+250^{\circ} \mathrm{C}$.

In the cryogenic region, while the oscillator functioned extremely well and demonstrated excellent output frequency stability with temperatures down to $-125{ }^{\circ} \mathrm{C}$, it exhibited intermittent operation in the range of $-125^{\circ} \mathrm{C}$ to $-130^{\circ} \mathrm{C}$, and it ceased to work as test temperatures dropped below $-130^{\circ} \mathrm{C}$. It appeared that this inoperability of the crystal oscillator at the extreme cryogenic temperature was transitory in nature since the circuit completely recovered when the test temperature was increased above $-130^{\circ} \mathrm{C}$.

The crystal oscillator was allowed to soak for at least 30 minutes at these decisive test temperatures in the environmental chamber prior to recording the data. Given the fact that this crystal oscillator is only rated for operation between $0{ }^{\circ} \mathrm{C}$ and $+230{ }^{\circ} \mathrm{C}$, this preliminary evaluation of its performance suggests that this range could be extended at the low temperature end provided more comprehensive and long term testing are done to corroborate the oscillator's performance. A typical waveform of the clock oscillator's frequency output at $22{ }^{\circ} \mathrm{C}$ is shown in Figure 3a.

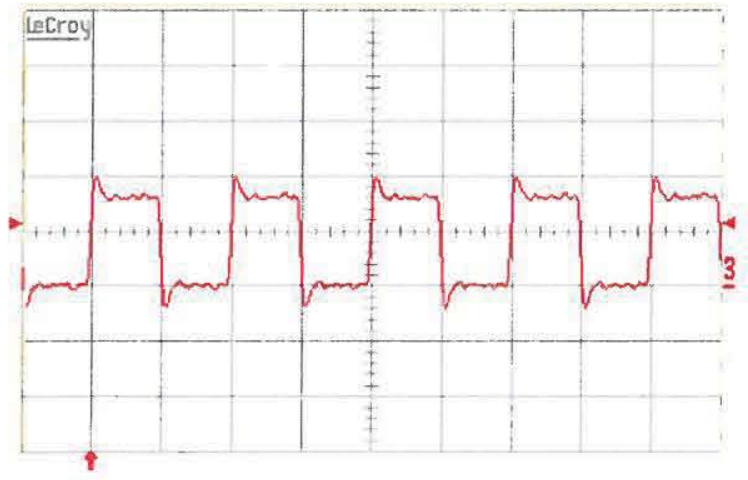

Figure 3a. Output waveform of the PX-570 crystal oscillator at room temperature. (Scale: Horizontal 50 ns/div, Vertical 2 V/div)
Similar to the frequency, the duty cycle of the output signal did not display any significant change with temperature as it retained a value around $50 \%$ throughout the whole test temperature range between $-125^{\circ} \mathrm{C}$ and $+230^{\circ} \mathrm{C}$, as depicted in Figure $3 \mathrm{~b}$.

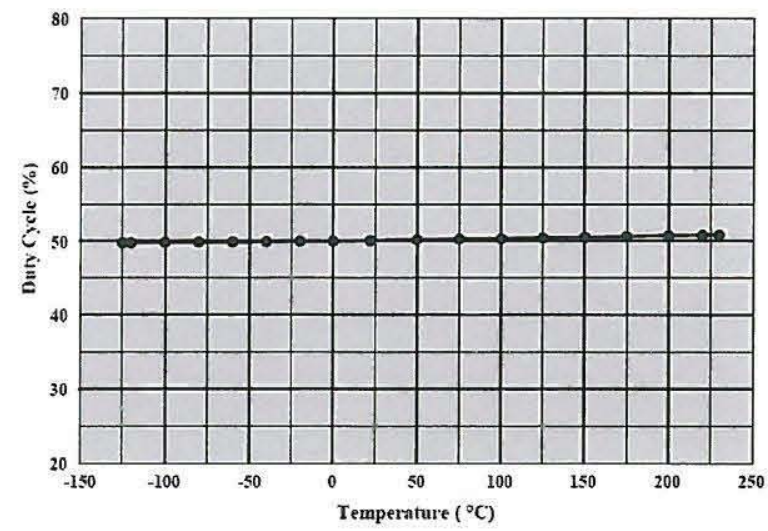

Figure $3 b$. The duty cycle of the PX-570 oscillator output clock signal shows almost no change over a temperature range of $-125^{\circ} \mathrm{C}$ to $+225^{\circ} \mathrm{C}$.

The rise time as well as the fall time of the output clock signal displayed similar but weak dependence on temperature (Figure 3c). Both the rise and fall times were found to exhibit gradual but very small reduction in their values as temperature was decreased below room temperature; and the reverse was true when the circuit was exposed to high temperatures. The changes occurring at high temperature were slightly more profound.

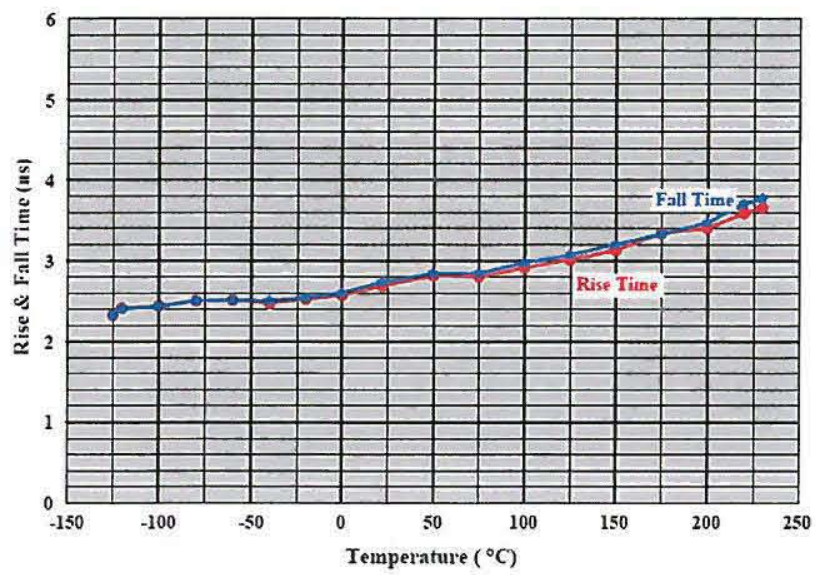

Figure 3c. Rise and fall times of oscillator's output signal versus temperature.

Negligible effect of test temperature on the supply current of the PX-570 crystal oscillator was observed 
as the value of the current hovered around $4.5 \mathrm{~mA}$ throughout the test temperature range between -125 ${ }^{\circ} \mathrm{C}$ and $+230^{\circ} \mathrm{C}$.

\section{Re-Start at Extreme Temperatures}

Re-start capability of the PX-570 crystal oscillator was investigated at the extreme test temperatures of $125^{\circ} \mathrm{C}$ and at $+230^{\circ} \mathrm{C}$. The oscillator was allowed to soak at each of those two temperatures, with electrical power off for at least 20 minutes. Power was then applied to the circuit, and measurements of the oscillator's output waveform characteristics and frequency were recorded. The oscillator circuit successfully operated under cold start at $-125^{\circ} \mathrm{C}$ as well as at the hot temperature of $+230^{\circ} \mathrm{C}$, and the data obtained was similar to those obtained earlier at these respective temperatures.

\section{Effects of Thermal Cycling}

The effects of thermal cycling were investigated by subjecting the crystal oscillator to a total of 12 cycles between $-125^{\circ} \mathrm{C}$ and $+230^{\circ} \mathrm{C}$ at a temperature change rate of $10^{\circ} \mathrm{C} /$ minute. Although this shortterm activity does not replace highly accelerated or life testing for reliability determination, it provides, nonetheless, some preliminary insight on the effect of thermal cycling on the device's behavior. During cycling, a dwell time of 20 minutes was applied at the extreme temperatures. Post-cycling measurements on the characteristics of the oscillator circuit were then performed at selected test temperatures.

Table II lists post-cycling data along with the data obtained prior to cycling. A comparison between preand post-cycling data reveals that this oscillator did not undergo any significant changes in its operational characteristics due to this limited cycling; as also evidenced by the consistency in the output waveforms shown in Figure 4 that were recorded at selected temperatures before and after the cycling. The thermal cycling also appeared to have no effect on the structural integrity of the device as no packaging damage was noted upon inspection.

Table II. Pre- and Post-Cycling Characteristics of the PX-570 Crystal Oscillator.

\begin{tabular}{|c|c|c|c|c|c|c|}
\hline $\mathrm{T}\left({ }^{\circ} \mathrm{C}\right)$ & Crcling & $\mathbf{f}(\mathrm{AHz})$ & Dutr cycle (\%) & $\mathrm{T}_{\text {rise }}$ (ns) & $\mathrm{T}_{\text {fall }}$ (us) & $\mathrm{I}_{\mathrm{S}}(\mathrm{mA})$ \\
\hline \multirow{2}{*}{125} & pre & 9.9993 & 50.08 & 2.69 & 2.73 & 4.4 \\
\cline { 2 - 7 } & post & 9.9994 & 50.1 & 2.8 & 2.78 & 4.45 \\
\hline \multirow{2}{*}{22} & pre & 9.9991 & 49.77 & 232 & 2.32 & 4.51 \\
& post & 9.9994 & 49.78 & 2.49 & 2.49 & 4.47 \\
\hline \multirow{2}{*}{+230} & pre & 10.0052 & 5084 & 3.65 & 377 & 4.89 \\
& post & 10.0048 & 50.83 & 3.65 & 3.72 & 5.02 \\
\hline
\end{tabular}
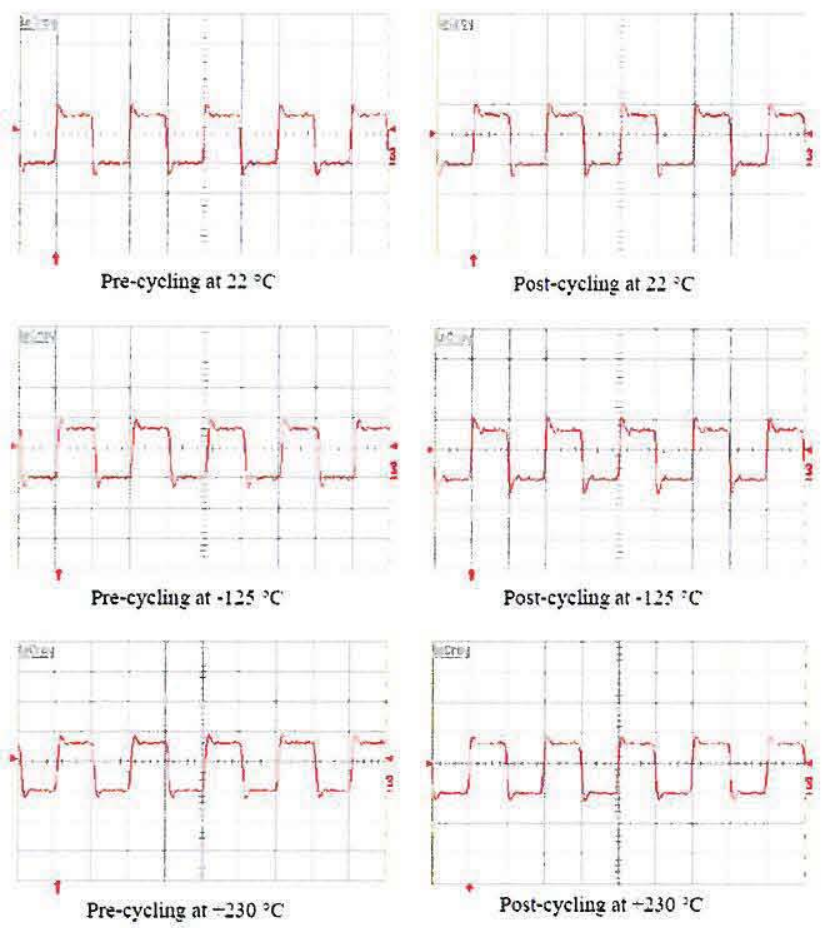

Figure 4. Pre- and post-cycling oscillator output waveforms at $22^{\circ} \mathrm{C},-125^{\circ} \mathrm{C}$, and $+230{ }^{\circ} \mathrm{C}$ show almost no significant differences.

\section{High Temperature Storage Test}

The PX-570 is designed for operating continuously at the extreme high temperature of 230 ${ }^{\circ} \mathrm{C}$ and to determine accelerated aging performance, a batch of nine oscillators were screened at temperatures of up to $250{ }^{\circ} \mathrm{C}$ with frequency data continuously collected for up to 5500 hours.

All nine oscillators that were tested passed the tests and had a frequency shift well within the expected limits as shown in Figure 5. The $250{ }^{\circ} \mathrm{C}$ screening test was stopped at 5500 hour mark mainly due to the degradation of the high temperature testing fixture that was custom designed for this test. Typical harsh environment applications, such as Oilfield Downhole Tools, require a 2000 hour product life at a maximum temperature of $225{ }^{\circ} \mathrm{C}$. The PX-570 clearly surpassed the expectation. 


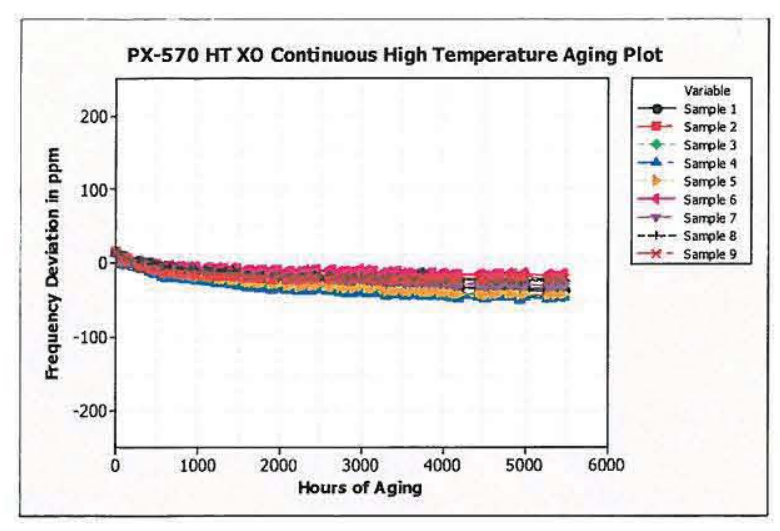

Figure 5. The output frequency deviation of the oscillators during an aging test of 5500 hours stayed well within the expected limits of +1-100 PPM.

\section{Shock and Vibration Performance}

In addition to an extreme operating temperature requirement, harsh environment applications also need to withstand high shock and vibration levels to ensure part survivability in the field. To prove the robustness of PX-570, a batch of 40 oscillators were subjected to three sets of independent shock and vibration tests developed by Vectron:

a) MIL-STD-883 mechanical sequence test

b) Progressive shock stress test

c) Progressive vibration stress test

All shock and vibration testing was conducted in the Vectron plant in Mount Holy Springs, PA.

The procedure for the mechanical sequence test starts with performing 1000 thermal cycles before the oscillators are subjected to the shock and vibration screening. Then tests per MIL-STD-883, Mechanical shock tests, using Method 2002 (1500 g, half-sine pulse shock) are performed along each of the three axes, followed by sine vibration (method 2007, $20 \mathrm{~g}$ peak, from $20 \mathrm{~Hz}$ to $2000 \mathrm{~Hz}$ ) with 4 minutes per cycle and four cycles for each axis.

Electrical tests and leak tests were conducted on all 40 PX-570 units before and after the shock and vibration screening. Clock output frequency data was captured and the results show that all 40 units passed within expected frequency shift range as shown in Figure 6. There were no significant changes in the output frequency following the mechanical sequence test and all devices were well within their specification limits

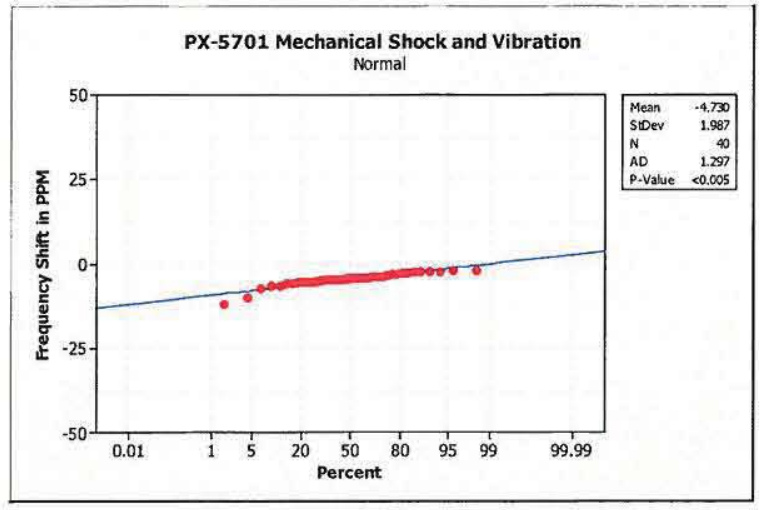

Figure 6. Mechanical shock and vibration testing of the oscillators shows that the shift in output frequency is well within the specified deviation limits.

\section{Progressive Shock Stress Testing}

Progressive stress testing is an effective test method to identify weakness by overstressing the devices at levels far exceeding the specified operating range. Vectron's original intent was to apply progressive stress test as a destructive test to identify the maximum screen level that the PX-570 device can survive up to. At the end of the testing, the test sample of five PX-570 devices continued to function normally.

During the shock stress test, PX-570 devices were subjected to $500 \mathrm{~g}, 1000 \mathrm{~g}, 1500 \mathrm{~g}, 3000 \mathrm{~g}, 4000 \mathrm{~g}$ and $5000 \mathrm{~g}$ mechanical shock levels, 3 shocks in each direction with a total of 18 shocks for each level. With six testing levels, each device accumulated a total of 108 mechanical shocks. Frequency data was recorded at the end of each shock level and the result of the tests showed that all five PX-570 devices passed within expected frequency shift as shown in Figure 7. 


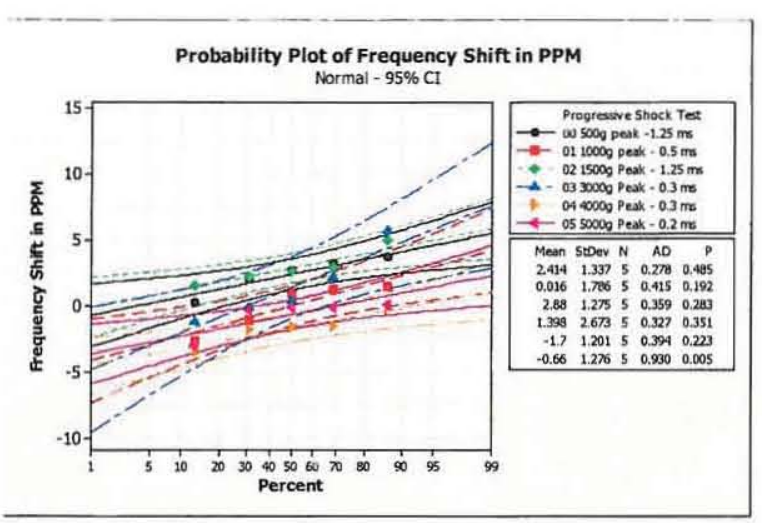

Figure 7. After accumulating 108 shocks, each of the five PX-570 oscillators stayed well within their frequency-shift limits.

\section{Progressive Vibration Stress Testing}

The progressive vibration stress test is a very demanding test for oscillators -- devices were tested continuously starting at their standard operating level and then the stress was increased in multiple steps to reach an extreme level. For the sine vibration stress test, the PX-570s were stressed at $20 \mathrm{~g}, 40 \mathrm{~g}, 60 \mathrm{~g}$ and $80 \mathrm{~g}$ levels at intervals from $10 \mathrm{~Hz}$ up to $2000 \mathrm{~Hz}, 20$ minutes per sweep, 12 sweeps per axis, with a total test duration of 12 hours at each level. With four testing levels, each device was tested and accumulated 48 hours of sine vibration testing. Frequency data was monitored during vibration and recorded at each vibration level. Test result for all 5 PX-570 devices show that the oscillators passed the test and their outputs were within the expected frequency shift range as shown in Figure 8a.

For the random vibration stress test, the PX-570s were tested at $20.71 \mathrm{grms}, 37.8 \mathrm{grms}, 53.79 \mathrm{grms}$, and 70 grms intervals from $10 \mathrm{~Hz}$ up to $2000 \mathrm{~Hz}$, at 15 minutes per axis, for a total test duration of 45 minutes at each level. With 4 testing levels, each device accumulated 180 minutes of test time under random vibration. Again, the frequency output was monitored during vibration and recorded at each vibration level. All five PX-570 oscillators passed testing and their outputs were within the expected frequency shift as shown in Figure 8b.

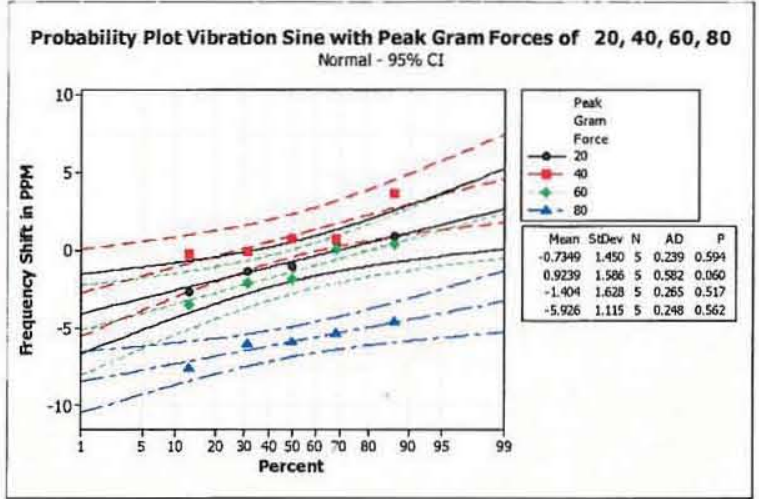

(a)

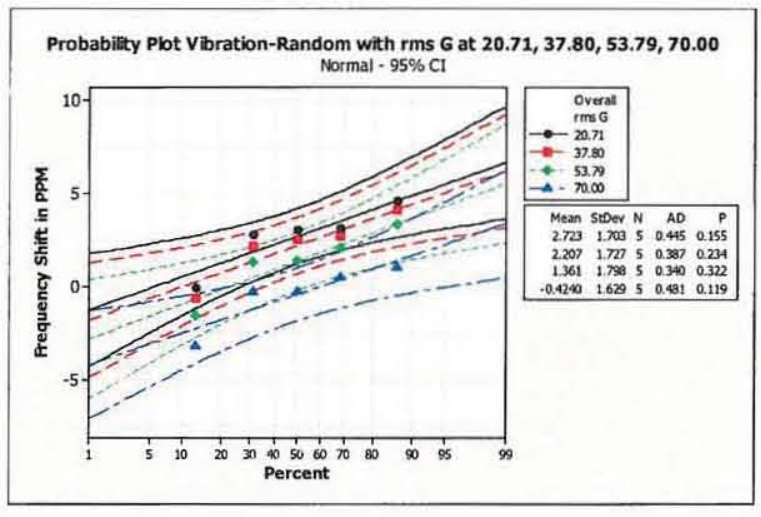

(b)

Figure 8. When subjected to vibration sine testing (a) and vibration random testing (b), the $P X-570$ oscillators exhibited minimal frequency shifts and stayed will within their specified error margins.

Typical "Downhole Tools" applications from oilfield service companies require electronics to operate with up to $1000 \mathrm{~g}$ mechanical shock and $20 \mathrm{~g}$ vibration levels. The progressive vibration test shows that the PX-570 devices can meet and surpass such requirements.

\section{ESD Threshold}

ESD (electrostatic discharge) damage to electronic components, caused by static build-up, lightning strikes and other conditions, is a well-known issue. To characterize the ESD threshold tolerance of the PX-570 devices, Vectron sent test samples to an outside testing facility, Integra Technologies to perform ESD testing per industrial standards - HBM per MIL-STD-883, Method 3015, 1000V \& 2000V and MM per V/JESD22-A115-A at 200V. Five PX570 oscillators were tested at each of the three 
voltage levels listed above with a total of 15 devices for the entire ESD threshold testing.

All the oscillators were tested before and following the ESD test. No significant changes in the critical device parameters were noted following the ESD test and all 15 devices performed well within the specification as shown in Figure 9a and Figure $9 b$.

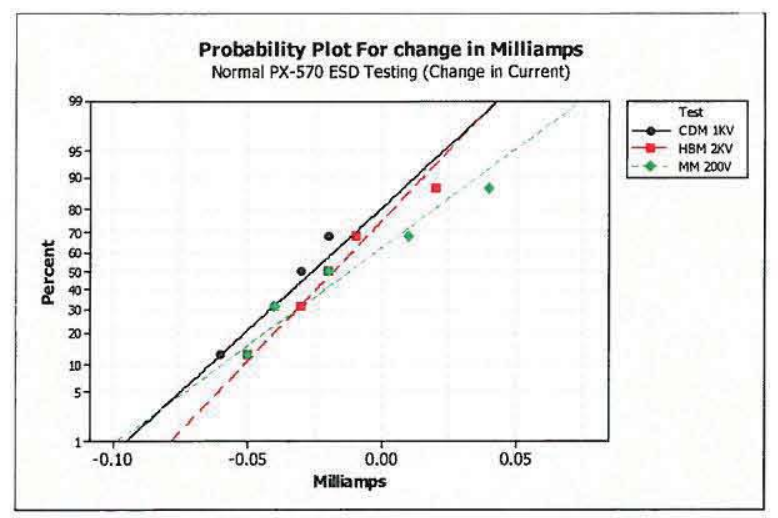

(a)

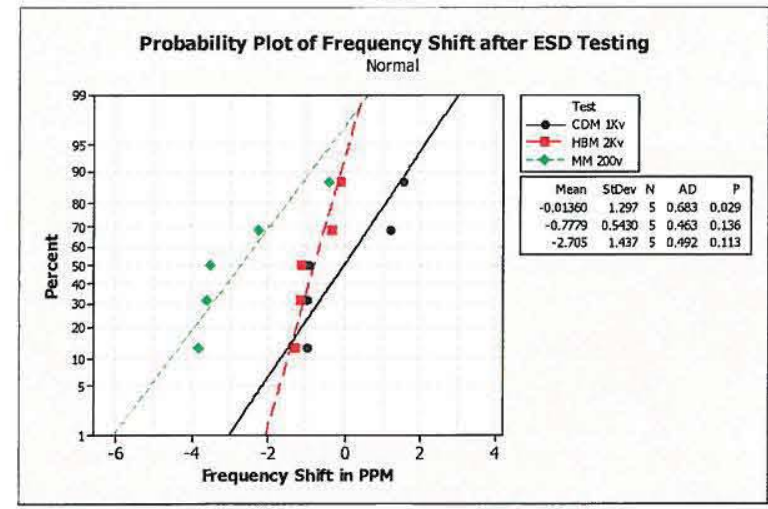

(b)

Figure 9. When subjected to ESD testing, the PX-570 oscillators exhibited minimal change in current (a) and minimal frequency shifts (b).

\section{Latch-Up Test}

In addition to the ESD threshold test, the oscillators were also subjected to latch-up testing by Integra Technologies. For testing, six PX-570 devices were tested per EIA/JESD78. The oscillators were measured before and following the latch-up tests. There were no significant changes in the critical device parameters such as change in current and frequency shift following the latch-up test and all six devices were still well within the specification limits as shown in Figure 10a and Figure 10b.

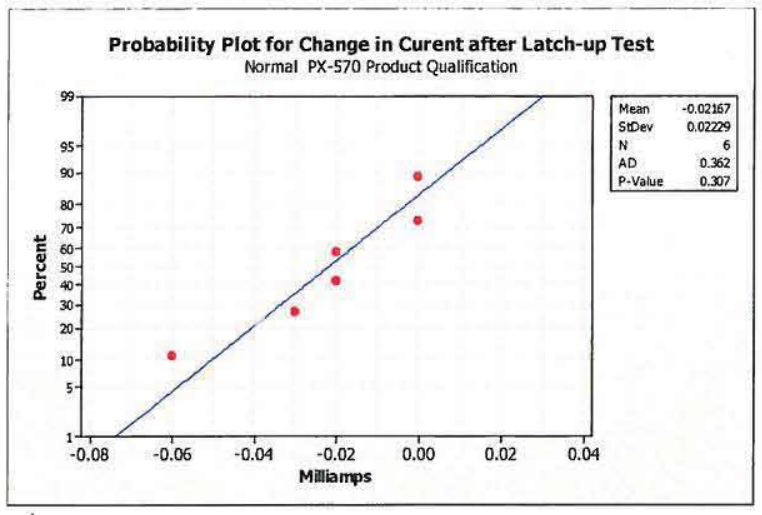

(a)

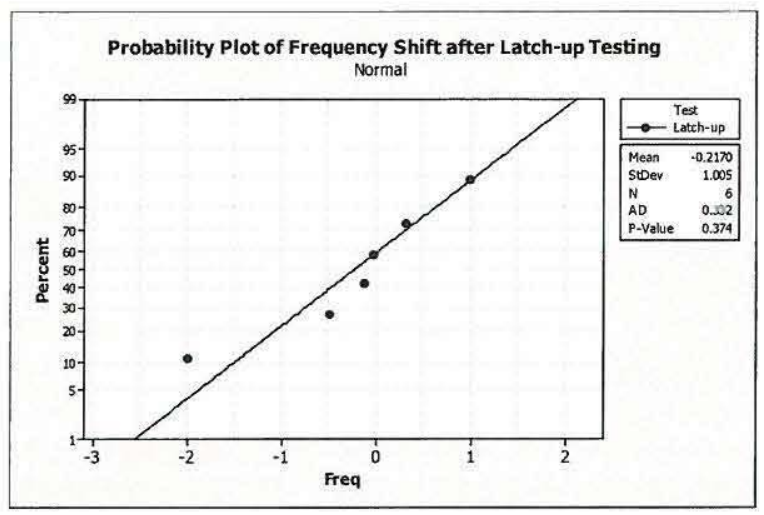

(b)

Figure 10. After latch-up testing, the six samples had minimal deviation from their current performance (a) or frequency output (b) vs. their pre-latch-up performance.

\section{Internal Moisture RGA Test}

Finally, the PX-570 oscillators were also subjected to internal moisture RGA tests per MILSTD-883, Method 1018. Three devices were tested by Atlantic Analytical Laboratory, Inc., but before testing the samples were subjected to an extensive high-temperature bake. All three devices passed the test with very low moisture content detected at low hundred ppm level inside the hermetically sealed PX570 package. Moisture test results are summed up in Table III. 
Table III: Moisture Test Results for Three PX-570 Oscillators

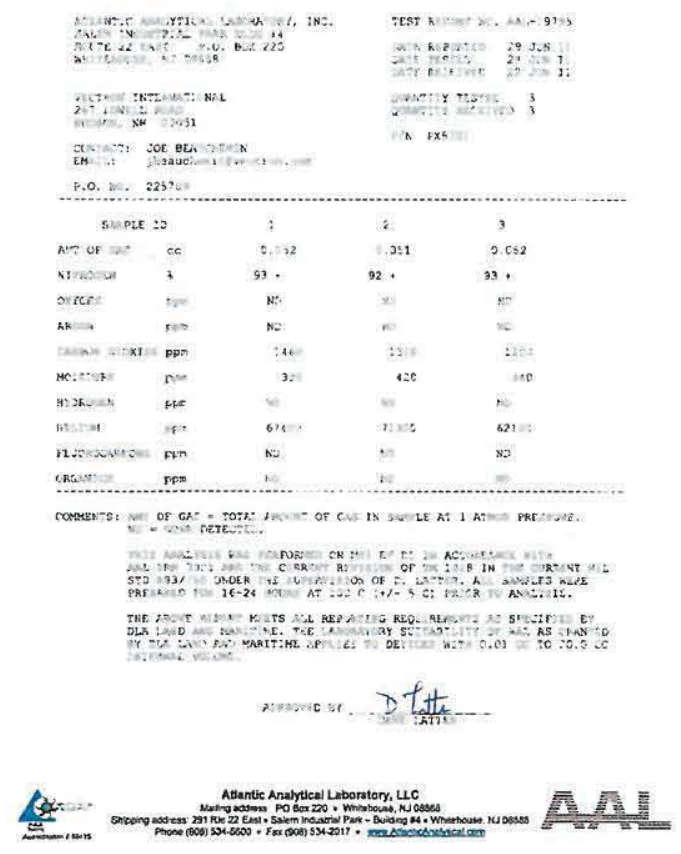

\section{Conclusions}

The crystal oscillator operated quite well with very good frequency stability over the temperature range of $-125{ }^{\circ} \mathrm{C}$ to $+230{ }^{\circ} \mathrm{C}$. This temperature operating range exceeded its recommended specified limits between $0{ }^{\circ} \mathrm{C}$ and $+230^{\circ} \mathrm{C}$. Similarly, the oscillator circuit experienced no change in its behavior after undergoing limited thermal cycling between $-125^{\circ} \mathrm{C}$ and $+230^{\circ} \mathrm{C}$, and was able to restart at the extreme temperatures. In addition, no damage was observed in the packaging material due to the extreme temperature exposure or thermal cycling. These preliminary results indicate that the device has the potential for operating also in cryogenic environments and in applications where wide-range thermal swings are present. Additional long-term testing could be done by NASA Glenn Research Center to fully establish the reliability of the oscillator and thus determine its suitability for use in space exploration missions under extreme temperature conditions. Furthermore, based on the data obtained from high temperature storage tests and extreme shock and vibration testing, the crystal oscillator will meet and exceed other harsh environment requirements for applications such as Oilfield Instrumentation, MIL-Aero and Avionics.
[1]. Vectron International, "PX-570 High Temperature Crystal Oscillator" data sheet, Rev: 11/2008. http://www.vectron.com

\section{Biographies}

Jacob $\mathbf{L i}$ received his BS in Electrical Engineering from the State University of New York at Buffalo, a MS in Manufacturing System Engineering and a MS in Management from Polytechnic Institute of New York University. He joined Vectron International, a Dover company in August 1987. Presently he is the Director of Engineering \& Business Development and he is responsible for leading the High Temperature Electronics product line in the company. Prior to that position, Jacob had various positions in Process Engineering, R\&D and Product Management and Marketing areas where he has been engaged in marketing, development and invention of new product platforms and technologies for Vectron. Development efforts include High Temperature Electronics, Evacuated Miniaturized Crystal Oscillator (EMXO), Harsh Environment Frequency Control Products and MEMS sensor technology. He has published technical papers in conferences and trade journals. He had served as Principal Investigator on two DARPA projects and has obtained two patents.

Richard L. Patterson has managed an extreme temperature electronics group at NASA Glenn Research Center for the past eighteen years. $\mathrm{He}$ received a BS in Physics from John Carroll University and an MS in Engineering Administration from Syracuse University. Richard has experience in nuclear rocket engines at Westinghouse Astronuclear Laboratory, electron optics at General Electric, diagnostic imaging at Picker Corp., and machine tool diagnostics and controls at Bendix Corp. He has published over 100 conference and technical papers, and he has obtained four patents.

Ahmad Hammoud currently holds the position of a Task Manager with ASRC Aerospace Corporation providing technical services and managerial support to the Space Processes and Experiment Division at the NASA Glenn Research Center in Cleveland, Ohio. His assignments involve engineering research and development, and program planning and management. He received his B.S., M.S., and Ph.D. degrees in Electrical and Computer Engineering from the State University of New York at Buffalo. He joined Sverdrup Technology, Inc. in 1988 as a Research Scientist in the Power Technology Division at the NASA Glenn Research Center. His expertise 
includes advanced electrical components and power systems for aerospace environments, high performance insulation and dielectrics, and radiation and thermal effects on materials and devices. Dr.
Hammoud has published over 18 papers in technical journals, 39 technical reports on the NASA NEPP Website, and over 80 presentations at leading international conferences. 